\title{
A cross-sectional survey of the nature and correlates of sleep disturbance in people with psoriasis
}

DOI:

10.1111/bjd.15469

Document Version

Accepted author manuscript

Link to publication record in Manchester Research Explorer

\section{Citation for published version (APA):}

Henry, A. L., Kyle, S. D., Chisholm, A., Griffiths, C. E. M., \& Bundy, C. (2017). A cross-sectional survey of the nature and correlates of sleep disturbance in people with psoriasis. The British journal of dermatology, 177(4), 1052-1059. https://doi.org/10.1111/bjd.15469

\section{Published in:}

The British journal of dermatology

\section{Citing this paper}

Please note that where the full-text provided on Manchester Research Explorer is the Author Accepted Manuscript or Proof version this may differ from the final Published version. If citing, it is advised that you check and use the publisher's definitive version.

\section{General rights}

Copyright and moral rights for the publications made accessible in the Research Explorer are retained by the authors and/or other copyright owners and it is a condition of accessing publications that users recognise and abide by the legal requirements associated with these rights.

\section{Takedown policy}

If you believe that this document breaches copyright please refer to the University of Manchester's Takedown Procedures [http://man.ac.uk/04Y6Bo] or contact uml.scholarlycommunications@manchester.ac.uk providing relevant details, so we can investigate your claim.

\section{OPEN ACCESS}


MR ALASDAIR LAWRIE HENRY (Orcid ID : 0000-0003-2217-3052)

Received Date : 04-Aug-2016

Revised Date : 07-Mar-2017

Accepted Date : 13-Mar-2017

Article type : Original Article

\section{A cross-sectional survey of the nature and correlates of sleep disturbance in people with psoriasis}

Running head: Sleep Disturbance in Psoriasis
A.L. Henry ${ }^{1,2,3}, \mathrm{~S}$
S.D. Kyle ${ }^{4}$, A. Chisholm ${ }^{5}$, C.E.M. Griffiths ${ }^{1,3,6}$, C. Bundy $y^{1,2,3}$
${ }^{1}$ Division of Musculoskeletal and Dermatological Sciences, University of Manchester, Manchester,
UK
${ }^{2}$ Manchester Centre for Health Psychology, University of Manchester, Manchester, UK
${ }^{3}$ Manchester Academic Health Science Centre, University of Manchester, Manchester, UK
${ }^{4}$ Sleep and Circadian Neuroscience Institute, Nuffield Department of Clinical Neurosciences,
University of Oxford, Oxford, UK
${ }^{5}$ Department of Psychological Sciences, University of Liverpool, Liverpool, UK
${ }^{6}$ Salford Royal NHS Foundation Trust, Manchester, UK

Corresponding author: Mr Alasdair L. Henry. Address: Room 1.725, Stopford Building, University of Manchester, Oxford Road, Manchester, M13 9PL. Tel: 01612751866

Email: alasdair.henry@postgrad.manchester.ac.uk

Funding source: This article presents independent research funded by The Psoriasis Association of Great Britain and Ireland (R117541).

\section{Conflicts of interest: None}

This article has been accepted for publication and undergone full peer review but has not been through the copyediting, typesetting, pagination and proofreading process, which may lead to differences between this version and the Version of Record. Please cite this article as doi: 10.1111/bjd.15469

This article is protected by copyright. All rights reserved. 


\section{What is already known about this topic?}

- Estimated rates of sleep disturbance in psoriasis vary widely

- Current research does not provide a comprehensive assessment of sleep, including possible physical and psychological factors associated with poor sleep.

\section{What does this study add?}

- Poor sleep is common, affecting over $75 \%$ of our sample.

- Poor sleep quality is associated with pre-sleep cognitive arousal, itch, low mood and pre-sleep somatic arousal.

- Possible treatment targets for improved sleep are identified.

\section{ABSTRACT}

\section{Background}

Research suggests that sleep disturbance is common in psoriasis. Despite 32 studies conducted in sleep, many demonstrate methodological flaws, often using unvalidated measurement, with no study examining multiple dimensions of sleep-wake functioning. Moreover, research has yet to comprehensively examine the range of physical and psychological factors that may affect sleep in people with psoriasis.

\section{Objective}

To characterise sleep disturbance using validated measures and identify physical and psychological predictors of sleep quality in people with psoriasis.

\section{Methods}

An online survey was conducted $\left(n=186 ; M_{a g e}=39.2\right)$ comprising validated measures assessing sleep (Pittsburgh Sleep Quality Index [PSQI], Berlin Questionnaire, Pre-Sleep Arousal Scale), chronotype (Morningness-Eveningness Questionnaire), mood (Hospital Anxiety and Depression Scale), itch (5-D Itch Scale) and psoriasis severity (Simplified Psoriasis Index). Group comparisons and regression analyses were used to examine predictors of poor sleep.

\section{Results}

Mean PSQI score was 9.24 (SD=4.32), with 76.3\% scoring above the threshold for poor sleep ( $\geq 6$ on the PSQI) and $32.5 \%$ scoring 'positive' for probable obstructive sleep apnoea. Poor sleep and high likelihood of OSA was associated with more severe psoriasis $(p<.05$;

This article is protected by copyright. All rights reserved. 
$\left.\eta^{2}=.07 ; \eta^{2}=.005\right)$. Cognitive arousal $(\beta=.264, p=.001)$, itch $(\beta=.260, p<.001)$ and depression $(\beta=.236, p=.001)$ were the most robust predictors of poor sleep quality which, together with somatic arousal ( $\beta=.168, p=.022)$, accounted for $43 \%$ of variance in PSQI scores.

\section{Conclusions}

Poor sleep is common in psoriasis and associated with psychological and physical factors. Rates of probable obstructive sleep apnoea are also high. Given the importance of restorative sleep for health, sleep complaints should receive greater clinical attention in the management of psoriasis.

\section{INTRODUCTION}

Psoriasis is a complex immune-mediated inflammatory disease primarily impacting on skin and affecting $2-3 \%$ of the population worldwide ${ }^{1}$. It has well established associations with a number of other conditions, including: cardiovascular disease (CVD) ${ }^{2}$, inflammatory bowel disease $^{3}$, psoriatic arthritis ${ }^{4}$, diabetes ${ }^{5}$, and depression and anxiety ${ }^{6}$. The disease burden of psoriasis is greater than other chronic dermatological conditions ${ }^{7}$ and equivalent to that experienced in cancer, CVD and arthritis populations ${ }^{8}$.

There is mounting interest in the relationship between sleep and psoriasis. A systematic review by our group showed that a high proportion (ranging from $0.05 \%$ to $87.5 \%$ ) of individuals with psoriasis may experience sleep disturbances ${ }^{9}$, which are associated with itch, psychological distress (low mood and anxiety), pain and obstructive sleep apnoea $(\mathrm{OSA})^{9}$. However the published literature demonstrates substantial variation in rates of disturbed sleep, and is limited by poor measurement of sleep, with many studies using unvalidated measures, in some cases just a single question. Indeed, lack of a comprehensive and valid examination of sleep, alongside incomplete data reporting ${ }^{910}$, has hindered our understanding of sleep in psoriasis.

Sleep disturbance, including OSA, is associated with a range of adverse health outcomes including elevated risk for a range of physical diseases, several of which people with psoriasis are already more susceptible to (e.g. diabetes ${ }^{11}$, hypertension ${ }^{12}, C V^{13}$ ). Moreover, sleep disturbance increases risk of psychological illness (e.g. depression ${ }^{14}$, anxiety ${ }^{15}$ ) and, over time, all-cause mortality ${ }^{16}$. Sleep is essential for metabolic ${ }^{17}$ and immunological health ${ }^{18}$, while sleep disturbance may be pro-inflammatory and impact on psoriasis activity ${ }^{18-}$

${ }^{20}$. Indirect evidence supporting the impact of sleep on inflammation in psoriasis comes from a recent epidemiological study showing that the presence of a comorbid sleep disorder

This article is protected by copyright. All rights reserved. 
increases CVD risk by $25 \%$ in psoriasis patients ${ }^{21}$. Additionally, relationships between circadian factors and psoriasis have been identified, with a longitudinal study reporting that regular night-shift work is associated with increased risk of developing psoriasis ${ }^{22}$. Circadian misalignment may disrupt normative metabolic and endocrine functioning, leading to adverse cardiometabolic complications, possibly through impairment of normal melatonin functioning. Melatonin, is involved in both sleep ${ }^{23}$, and regulates inflammatory responses ${ }^{24}$, and may lead to increased risk of psoriasis onset if chronically disrupted ${ }^{22}$.

Based upon the strong links identified between sleep, health and psoriasis, a multidimensional assessment of sleep in this population is warranted. Whilst previous studies provide evidence of sleep disturbance in psoriasis, few studies have measured multiple domains of sleep disturbance in psoriasis patients using validated tools ${ }^{9}$. A range of validated measures must be used to comprehensively assess the range of sleep dimensions, including sleep timing (i.e. chronotype), sleep quality, sleep continuity and sleep duration. Due to the limited appraisal of potential predictors of sleep quality in psoriasis we sought to examine the role of thesein predicting poor sleep focusing on variables associated with poor sleep in psoriasis including low mood ${ }^{14152526}$, anxiety ${ }^{152728}$ and itch ${ }^{29} 30$ and more generally, pre-sleep arousa $\left.\right|^{31-33}$. Our aims were as follows: firstly to examine multiple dimensions of sleep-wake functioning in a representative community-based sample, and secondly, to identify the predictors of sleep disturbance, focusing on both physical and psychological variables known to interact with sleep in psoriasis.

\section{METHODS}

\section{Design}

We conducted a cross-sectional online survey using SelectSurvey.NET (v4.146.001, ClassApps, Overland Park, KS, USA). This allowed an international sample to access the survey, and enabled participants to complete it in their own time.

\section{Recruitment}

Links for the survey were distributed via social media sites by the Psoriasis Association of Great Britain and Ireland, the National Psoriasis Foundation, the Canadian Psoriasis Association, The British Skin Foundation, and were posted on Facebook groups for members of the New Zealand Psoriasis Association along with other psoriasis support groups. Additional snowballing techniques were used: the survey link was distributed by the

This article is protected by copyright. All rights reserved. 
IMPACT research group's (www.impactpsoriasis.org.uk) professional contacts, an existing psoriasis research database and through posters placed in a UK University.

\section{Participants}

Inclusion criteria included (i) a diagnosis of plaque psoriasis from a healthcare professional, (ii) $\geq 18$ years old and (iii) a good understanding of English. The survey was available to any individual with psoriasis regardless of whether or not they were experiencing sleep disturbance to ensure that variation in sleep quality was captured.

\section{Procedure and analysis}

Upon opening the survey link, participants were presented with an information sheet explaining the study's aims, content and research team contact details. Consent was provided online immediately preceding participation. Demographic questions, measures relating to sleep, mood, psoriasis, and itch were presented for completion and included:

Pittsburgh Sleep Quality Index (PSQI) ${ }^{34} 35$ - Assesses sleep quality and disturbance over one month. It consists of 19 items scored across 7 components which yield a global score ranging from 0 to 21 . A score of $\leq 5$ indicates normal sleep whereas $\geq 6$ indicates poor sleep.

Berlin Questionnaire ${ }^{36}$ - A screening questionnaire used to assess risk for the development of OSA. It consists of 3 categories containing a total of 10 items. Positive scores in $>2$ categories indicate high OSA risk and low risk if $<1$ category is positive.

Morningness-Eveningness Questionnaire (MEQ) ${ }^{37}$ - Ascertains when an individual's peak alertness is (morning, evening or in between) over 19 multiple choice questions. Scores correspond to the following chronotypes: 16-30 - definite evening, 31-41 - moderate evening, 42-58 - intermediate, 59-69 - moderate morning, and 70-86 - definite morning.

Pre-Sleep Arousal Scale (PSAS) ${ }^{38} 39$ - Quantifies cognitive and somatic arousal during the pre-sleep period. It consists of 16 items across 2 subscales, one assessing cognitive arousal and the other somatic arousal with scores ranging from 8 to 40 . A higher score indexes greater pre-sleep arousal.

Hospital Anxiety and Depression Scale (HADS) ${ }^{40} 41$ - An established measure of depression and anxiety comprising 14 items, with 7 relating to depression and 7 relating to anxiety (each subscale scored between 0 and 21). A higher score reflects greater distress. A cut-off score of 9 for each subscale indicates 'caseness' for probable clinical levels of ditress ${ }^{41}$.

This article is protected by copyright. All rights reserved. 
Simplified Psoriasis Index-Severity Score (SPI-S) $)^{42}$ - A self-assessment of psoriasis severity asking participants to rate the extent and plaque thickness which are multiplied to obtain a severity score. Scores range from 0-50 with a higher score indicating more severe psoriasis. An SPI-S score of $<5,<10,>18,>19$ and $>20$ is equivalent to a Psoriasis Area Severity Index score of $<5,<10,>15,>18$ and $>20$ respectively ${ }^{43}$.

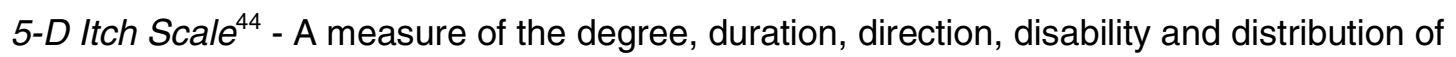
itch. It can be calculated to provide a global score of itch severity and impact. Scores can range from 5 (no itch) to 25 (severe itch).

All questions on each page had to be completed in order to progress to the next page. Ethical approval for this study was obtained in June 2015 (ref: 15/LO/1052).

\section{Statistical analyses}

Descriptive data were obtained for all variables. Normality was assessed and due to positively skewed data, bootstrapping based upon 5000 replications was applied to tests using psoriasis severity. Associations between questionnaire variables were tested using Pearson's product moment correlations and point-biserial correlations when using OSA probability. Independent t-tests were used to compare psoriasis severity scores for normal (PSQI $\leq 5)$ and poor sleepers (PSQI $\geq 6$ ) and to compare psoriasis severity scores between those with a high and low likelihood for OSA. A one-way analysis of variance (ANOVA) compared psoriasis severity scores for morning, intermediate and evening chronotype groups. Relative between-group effect sizes, expressed as eta-squared $\left(\eta^{2}\right)$, were applied to estimate and compare the magnitude of observed effects. To examine which factors predicted poor sleep a multiple linear regression was performed for all variables that correlated with sleep $(r \geq .4)^{45}$ entered simultaneously. All analyses were conducted on SPSS (v22.0, IBM Corporation; Armonk, NY, USA).

\section{RESULTS}

\section{Sample characteristics}

One hundred and eighty-six people (140 [75.3\%] female; $M_{\text {age }}=39$ years; range 18-70 years) from 15 countries (UK, USA, Canada, New Zealand, Australia, Ireland, Germany, Greece, Argentina, Egypt, India, France, Italy, Denmark, Puerto Rico) completed the survey between June 2015 and January 2016, providing complete data. Partial data was obtained from 241 participants, however, many dropped out in the initial pages of the survey. Rather

This article is protected by copyright. All rights reserved. 
than substitute data for partially complete responses we chose to use complete data only. Psoriasis severity was predominantly mild with a sample mean SPI-S score of 9.56 $(S D=8.58)$. Mean score for the depression and anxiety subscales were below the clinical threshold at $6.52(\mathrm{SD}=4.24)$ and $8.56(\mathrm{SD}=4.34)$ respectively ${ }^{41}$.

\section{Sleep Characteristics}

Of 186 participants, $76.3 \%(n=142)$ were classified as poor sleepers with the sample having a mean PSQI score of $9.24, \mathrm{SD}=4.32$. Sixty-one (32.6\%) participants had a high probability of OSA as determined by the BQ. Consistent with elevated OSA probability, the mean BMI for the sample was high at $30.7 \mathrm{~kg} / \mathrm{m}^{2}$, with $26.4 \%$ overweight $\left(>25 \mathrm{~kg} / \mathrm{m}^{2}\right)$ and $44.8 \%$ obese $\left(>30 \mathrm{~kg} / \mathrm{m}^{2}\right)$. Regarding pre-sleep arousal, the mean score for the cognitive subscale was $21.01(S D=7.5)$ and $14.53(S D=5.85)$ for the somatic subscale. The mean MEQ score for the sample was $51.43(\mathrm{SD}=9.98)$, with the majority possessing an intermediate chronotype $(62.9 \%)$, followed by morning $(23.1 \%)$ then evening (14\%).

Participants' mean total sleep time was $371.3(\mathrm{SD}=89.14)$ minutes with $83.3 \%$ classified as short sleepers ( $<7$ hours), $14.5 \%$ as normal sleepers (7-9 hours) and $2.2 \%$ as long sleepers $(>9 \text { hours })^{46}$. Mean sleep efficiency for the sample was relatively poor at $75.34 \%$ $(S D=17.33)$, with a mean sleep onset latency of $42.37(S D=44.04)$ minutes. Reported sleep problems related to poor subjective sleep quality (51\%) two or more times per week, difficulties initiating sleep (52.1\%) two or more times per week and difficulty with both maintaining sleep along with early awakening from sleep (79\%) two or more times per week. Participants' also reported difficulties sleeping due to being too hot and experiencing pain. Further detail on these can be seen in $\mathrm{S} 1$.

Descriptive data for all variables are presented in Table 1. Comparisons of mean scores for normal and poor sleepers for each continuous measure can be seen in Figure 1.

A significant difference was present in psoriasis severity scores between normal sleepers $(M=6.36 ; S D=5.44)$ and poor sleepers $\left(M=10.55\right.$; $\left.S D=9.14 t(184)=3.73, p<.001, \eta^{2}=.07\right)$, with poor sleepers having significantly higher psoriasis severity scores. Similarly, individuals with a high probability of $\mathrm{OSA}(\mathrm{M}=11.58, \mathrm{SD}=10.30)$ had significantly higher psoriasis severity scores than those with a low probability $\left(M=8.58, S D=7.45 \mathrm{t}(184)=2.03, \mathrm{p}<.05, \eta^{2}=.005\right)$. There were no significant differences in psoriasis severity scores between morning $(M=7.75$, $S D=6.86)$, intermediate $(M=10.19, S D=8.69)$, and evening $(M=9.69, S D=10.39)$ chronotype groups, $\left(p=.281 ; \eta^{2}=.014\right)$.

This article is protected by copyright. All rights reserved. 


\section{Predictors of sleep quality}

Next, we evaluated the contribution of variables (age, sex, BMI, psoriasis severity, mood, itch, pre-sleep arousal, chronotype and OSA risk) to variation in sleep quality. Sleep quality was significantly positively correlated with psoriasis severity, anxiety, depression, itch, somatic arousal and cognitive arousal and negatively correlated with chronotype (Table 2). All variables except psoriasis severity, chronotype and OSA probability correlated with sleep quality at $r \geq .4$. Therefore, anxiety, depression, itch, and somatic and cognitive arousal were included in the subsequent regression analysis (Table 3 ).

Multiple regression analysis indicated that cognitive arousal $(\beta=.264, p<.05)$, itch $(\beta=.260$, $p<.0001)$, depression $(\beta=.236, p<.05)$ and somatic arousal $(\beta=.168, p<.05)$ were independent predictors of sleep quality, together accounting for $43 \%$ of variance in PSQI scores.

\section{DISCUSSION}

The aim of this study was to characterise sleep in psoriasis and to examine the predictors of sleep quality. Our results show that poor sleep quality may be more common in psoriasis $(76.3 \%)$ than estimates in the general population (30-50\% $)^{47}$. Indeed, sleep quality and sleep efficiency were worse than previously reported in psoriasis ${ }^{48-50}$ or diabetes samples ${ }^{51}$ and equivalent to that shown in a psoriatic arthritis sample ${ }^{52}$. Additionally, we observed a high probability of OSA in our sample (32.5\%), again at a rate higher than the prevalence in the general population $(3-7 \%)^{53}$, although somewhat lower than the rate of around $50 \%$ reported in other psoriasis samples ${ }^{5455}$.

Short sleep duration ( $<7$ hours) was common in our sample, reported by the majority (83.3\%). Short sleep duration has well established links with negative health consequences including obesity ${ }^{56}$, diabetes ${ }^{57} 58$ and hypertension ${ }^{59}$ and thus may contribute to increased disease burden. Participants reported difficulties initiating and maintaining sleep, alongside early awakening with an inability to resume sleep; these are core features of insomnia ${ }^{60}$. Indeed, there was high pre-sleep cognitive and somatic arousal in our sample, at least as high as clinical insomnia patients ${ }^{61}$. Pre-sleep arousal is a known feature of insomnia, frequently precipitating and contributing to sleep difficulties ${ }^{31}{ }^{62}$ manifesting as cognitive (rumination, worry and negative emotion) ${ }^{32}$, somatic (elevated sympathetic activity,

This article is protected by copyright. All rights reserved. 
metabolic rate and hypothalamic-pituitary-adrenal axis activity) ${ }^{63-65}$ and cortical (increased brain metabolism and high-frequency EEG activity) ${ }^{6667}$ hyper-arousal.

The elevated OSA probability present in our sample is consistent with the high mean BMI score found, with obesity a known risk factor for $\mathrm{OSA}^{68}$ and common in people with psoriasis $^{69}$. It is likely that lifestyle factors (e.g. obesity, physical inactivity) are involved and may contribute to this elevated risk $^{55}$. Nevertheless, it has been proposed that psoriasis and OSA are linked bi-directionally via inflammatory pathways, with both disorders demonstrating increased concentrations of interleukin (IL)-17, IL-6 and tumour necrosis factor (TNF)- $\alpha^{70-73}$. Whilst the precise mechanisms linking OSA and psoriasis remain unclear, there is some evidence suggesting links between lifestyle factors and CVD/hypertensionmay underlie this elevated risk ${ }^{74}$. It is worth mentioning that OSA estimates in this study are lower than reported elsewhere ${ }^{9}$ and may be due to the use of a self-report measure (Berlin Questionnaire) rather than polysomnography to assess OSA. However, the Berlin Questionnaire has proven validity, and a moderate-strong positive predictive value, ranging from $.72^{75}$ to $.89^{36}$. Given that OSA is a known risk factor for $C V D^{76}$, ischemic stroke ${ }^{77}$, road traffic accidents ${ }^{78}$ and hypertension ${ }^{79}$ we suggest that sleep disordered breathing is queried in patients with psoriasis to facilitate appropriate diagnosis and treatment.

Cognitive arousal, itch, depression and somatic arousal were identified as key predictors of sleep quality. Elevated arousal in the pre-sleep period is associated with sleep difficulties in insomnia and healthy individuals, contributing to increased sleep onset latency, reduced sleep efficiency and total sleep time and sleep-state misperception ${ }^{31-33}$. Although speculative, a number of factors may contribute to elevated arousal in psoriasis including disease-related rumination and worry, and monitoring of somatic symptoms, such as itch. Further arousal may stem from disrupted emotional regulation, resulting in negatively-toned emotional activity with sleep disturbances known to modulate emotional responses ${ }^{80} 81$. It is likely that anxiety did not emerge as a significant predictor due to the probable shared variance between the HADS-A and PSAS-C subscales. The content of this elevated arousal in the pre-sleep period could be investigated further, examining psoriasis-specific factors. Itch and associated scratching have been reported as disrupting sleep in psoriasis and other pruritic conditions, with scratching occurring throughout the sleep period ${ }^{82-85}$. Evidence suggests conditioned scratching activity can occur during sleep, with nocturnal scratching reported as a distinct parasomnia in a number of $\operatorname{cases}^{86}$. Moreover, itch has strong links with mood $^{87}$, with depression amplifying itch perception ${ }^{88}$. In addition, well-established links between depression and sleep exist, with low mood and insomnia interacting bidirectionally ${ }^{14}$ ${ }^{89}$ suggesting the existence of shared aetiology ${ }^{1426}$. Future research could focus on

This article is protected by copyright. All rights reserved. 
prospectively examining the causal direction between these predictors and poor sleep with the aim of identifying possible mediating pathways.

A key strength of this study is that it provides a multidimensional assessment of sleep using validated measures in an international sample. Despite this, there are limitations that must be considered. First, our study may have been subject to selection bias with people that experience sleep disruption having a greater motivation to participate. We attempted to minimise this by inviting all individuals with psoriasis regardless of sleep status to participate. Moreover, although the majority of our sample had mild psoriasis, magnitude of sleep disturbance and high levels of pre-sleep arousal suggest that poor sleep is a prevalent issue in this group. We believe the distribution of psoriasis severity observed in this study is sufficiently similar to that found elsewhere ${ }^{90}$. It is unclear, however, why there was a predominance of women participating in the study. It could be speculated that this is due to a higher prevalence of insomnia, thus may be the result of selection bias ${ }^{91}$. Indeed, evidence suggests women are more likely to respond to survey research with similar gender distributions to those encountered here observed in other sleep-related survey studies ${ }^{92} 93$. It is also unclear why we obtained a low participation rate relative to the recruitment efforts.

Over 11,800 individuals engaged with the survey link, however 11,471 did not continue past the information sheet. We are unsure why this is, however, a contributing factor may have been the number of questions included. Another significant limitation of this study is the lack of a control group, limiting our ability to generalise the prevalence of sleep disturbance found in this study to the psoriasis population as a whole. A further limitation stems from the use of subjective sleep measures, which, whilst valid, were retrospective in nature and thus may be subject to recall biases which is a limitation of cross-sectional research. Additionally, we did not examine other sleep disorders such as sleep-related movement disorders, circadian rhythm disorders, parasomnias or excessive daytime sleepiness; thus hidden sleep pathology may not have been detected. Finally, with the study being cross-sectional we are limited in our ability to explore the causal ordering of variable relationships.

In summary, our findings suggest that sleep disturbance more common than previously thought in psoriasis and that it is associated with a range of psychological and physical factors. Whilst a handful of studies have shown improvements in sleep in psoriasis following administration of biologic medication ${ }^{94} 95$, this should be combined with psychological therapies specifically targeting the modifiable factors identified here including, including itch, negative mood and pre-sleep arousal. Therapeutic focus on these variables may lead to improvements in sleep in people with psoriasis.

This article is protected by copyright. All rights reserved. 


\section{REFERENCES}

1. Parisi R, Symmons DP, Griffiths CE, et al. Global epidemiology of psoriasis: a systematic review of incidence and prevalence. Journal of Investigative Dermatology 2013;133(2):377-85.

2. Parisi $\mathrm{R}$, Rutter MK, Lunt $\mathrm{M}$, et al. Psoriasis and the risk of major cardiovascular events: cohort study using the clinical practice research datalink. Journal of Investigative Dermatology 2015.

3. Cohen A, Dreiher J, Birkenfeld S. Psoriasis associated with ulcerative colitis and Crohn's disease. Journal of the European Academy of Dermatology and Venereology 2009;23(5):561-65.

4. Gladman D, Antoni C, Mease P, et al. Psoriatic arthritis: epidemiology, clinical features, course, and outcome. Annals of the Rheumatic Diseases 2005;64(suppl 2):ii14-ii17.

5. Cohen A, Dreiher J, Shapiro Y, et al. Psoriasis and diabetes: a population-based cross-sectional study. Journal of the European Academy of Dermatology and Venereology 2008;22(5):58589.

6. Kurd S, Troxel A, Crits-Christoph $\mathrm{P}$, et al. The risk of depression, anxiety, and suicidality in patients with psoriasis: a population-based cohort study. Archives of Dermatology 2010;146(8):89195.

7. Evers A, Lu Y, Duller P, et al. Common burden of chronic skin diseases? Contributors to psychological distress in adults with psoriasis and atopic dermatitis. British Journal of Dermatology 2005;152(6):1275-81.

8. Rapp SR, Feldman SR, Exum ML, et al. Psoriasis causes as much disability as other major medical diseases. Journal of the American Academy of Dermatology 1999;41(3):401-07.

9. Henry A, Kyle S, Bhandari S, et al. Measurement, classification and evaluation of sleep disturbance in psoriasis: A systematic review PLoS One 2016;11(6):e0157843.

10. Henry AL, Kyle SD, Bundy C. A call for improved sleep research in psoriasis populations. International Journal of Dermatology 2016.

11. Spiegel K, Knutson K, Leproult $R$, et al. Sleep loss: a novel risk factor for insulin resistance and Type 2 diabetes. Journal of Applied Physiology 2005;99(5):2008-19.

12. Palagini L, Maria Bruno R, Gemignani A, et al. Sleep loss and hypertension: a systematic review. Current Pharmaceutical Design 2013;19(13):2409-19.

13. Mullington JM, Haack $M$, Toth $M$, et al. Cardiovascular, inflammatory, and metabolic consequences of sleep deprivation. Progress in Cardiovascular Diseases 2009;51(4):294-302.

14. Baglioni C, Battagliese G, Feige B, et al. Insomnia as a predictor of depression: a meta-analytic evaluation of longitudinal epidemiological studies. Journal of Affective Disorders 2011;135(1):10-19.

15. Neckelmann D, Mykletun A, Dahl AA. Chronic insomnia as a risk factor for developing anxiety and depression. Sleep 2007;30(7):873.

16. Cappuccio FP, D'Elia L, Strazzullo $P$, et al. Sleep duration and all-cause mortality: a systematic review and meta-analysis of prospective studies. Sleep 2010;33(5):585.

17. Van Cauter E, Spiegel K, Tasali E, et al. Metabolic consequences of sleep and sleep loss. Sleep Medicine 2008;9:S23-S28.

18. Irwin MR. Why sleep is important for health: a psychoneuroimmunology perspective. Psychology 2015;66(1):143.

19. Irwin MR, Olmstead R, Carroll JE. Sleep disturbance, sleep duration, and inflammation: a systematic review and meta-analysis of cohort studies and experimental sleep deprivation. Biological Psychiatry 2015.

20. Vgontzas A, Zoumakis M, Papanicolaou D, et al. Chronic insomnia is associated with a shift of interleukin- 6 and tumor necrosis factor secretion from nighttime to daytime. Metabolism 2002;51(7):887-92.

21. Chiu H-Y, Hsieh C-F, Chiang Y-T, et al. Concomitant sleep disorder significantly increased the risk of cardiovascular disease in patients with psoriasis. PLOS One 2016.

This article is protected by copyright. All rights reserved. 
22. Li W, Qureshi AA, Schernhammer ES, et al. Rotating night shift work and risk of psoriasis in US women. Journal of Investigative Dermatology 2013;133(2):565.

23. Cajochen C, Kräuchi K, Wirz-Justice A. Role of melatonin in the regulation of human circadian rhythms and sleep. Journal of neuroendocrinology 2003;15(4):432-37.

24. Esposito E, Cuzzocrea S. Antiinflammatory activity of melatonin in central nervous system. Current neuropharmacology 2010;8(3):228-42.

25. Franzen PL, Buysse DJ. Sleep disturbances and depression: risk relationships for subsequent depression and therapeutic implications. Dialogues in Clinical Neuroscience 2008;10(4):473.

26. Manber R, Chambers AS. Insomnia and depression: a multifaceted interplay. Current Psychiatry Reports 2009;11(6):437-42.

27. Ohayon MM, Roth T. Place of chronic insomnia in the course of depressive and anxiety disorders. Journal of Psychiatric Research 2003;37(1):9-15.

28. Ramsawh HJ, Stein MB, Belik S-L, et al. Relationship of anxiety disorders, sleep quality, and functional impairment in a community sample. Journal of Psychiatric Research 2009;43(10):926-33.

29. Bender BG, Ballard R, Canono B, et al. Disease severity, scratching, and sleep quality in patients with atopic dermatitis. Journal of the American Academy of Dermatology 2008;58(3):415-20.

30. Sherry HY, Attarian H, Zee P, et al. Burden of Sleep and Fatigue in US Adults With Atopic Dermatitis. Dermatitis 2016;27(2):50-58.

31. Robertson JA, Broomfield NM, Espie CA. Prospective comparison of subjective arousal during the pre-sleep period in primary sleep-onset insomnia and normal sleepers. Journal of Sleep Research 2007;16(2):230-38.

32. Wuyts J, De Valck E, Vandekerckhove $M$, et al. The influence of pre-sleep cognitive arousal on sleep onset processes. International Journal of Psychophysiology 2012;83(1):8-15.

33. Tang NK, Harvey AG. Effects of cognitive arousal and physiological arousal on sleep perception. Sleep 2004;27(1):69-78.

34. Buysse DJ, Reynolds CF, Monk TH, et al. The Pittsburgh Sleep Quality Index: a new instrument for psychiatric practice and research. Psychiatry Research 1989;28(2):193-213.

35. Backhaus J, Junghanns K, Broocks A, et al. Test-retest reliability and validity of the Pittsburgh Sleep Quality Index in primary insomnia. Journal of Psychosomatic Research 2002;53(3):73740.

36. Netzer NC, Stoohs RA, Netzer CM, et al. Using the Berlin Questionnaire to identify patients at risk for the sleep apnea syndrome. Annals of Internal Medicine 1999;131(7):485-91.

37. Horne JA, Ostberg $O$. A self-assessment questionnaire to determine morningness-eveningness in human circadian rhythms. International Journal of Chronobiology 1975;4(2):97-110.

38. Nicassio PM, Mendlowitz DR, Fussell JJ, et al. The phenomenology of the pre-sleep state: the development of the pre-sleep arousal scale. Behaviour Research and Therapy 1985;23(3):263-71.

39. Jansson-Fröjmark M, Norell-Clarke A. Psychometric properties of the Pre-Sleep Arousal Scale in a large community sample. Journal of Psychosomatic Research 2012;72(2):103-10.

40. Zigmond AS, Snaith RP. The hospital anxiety and depression scale. Acta Psychiatr Scand 1983;67(6):361-70.

41. Bjelland I, Dahl AA, Haug TT, et al. The validity of the Hospital Anxiety and Depression Scale: an updated literature review. Journal of Psychosomatic Research 2002;52(2):69-77.

42. Chularojanamontri L, Griffiths CE, Chalmers RJ. The Simplified Psoriasis Index (SPI): a practical tool for assessing psoriasis. Journal of Investigative Dermatology 2013;133(8):1956-62.

43. Chularojanamontri L, Griffiths CE, Chalmers RJ. Responsiveness to change and interpretability of the simplified psoriasis index. Journal of Investigative Dermatology 2014;134(2):351-58.

44. Elman S, Hynan L, Gabriel V, et al. The 5-D itch scale: a new measure of pruritus. British Journal of Dermatology 2010;162(3):587-93.

This article is protected by copyright. All rights reserved. 
45. Cohen J, Cohen P, West SG, et al. Applied multiple regression/correlation analysis for the behavioral sciences: Routledge, 2013.

46. Watson NF, Badr MS, Belenky G, et al. Recommended amount of sleep for a healthy adult: a joint consensus statement of the American Academy of Sleep Medicine and Sleep Research Society. Sleep 2015;38(6):843-4.

47. Leger D, Poursain B, Neubauer D, et al. An international survey of sleeping problems in the general population. Current Medical Research and Opinion 2007;24(1):307-17.

48. Shutty BG, West C, Huang KE, et al. Sleep disturbances in psoriasis. Dermatology Online Journal 2013;19(1).

49. Stinco G, Trevisan G, Piccirillo F, et al. Psoriasis vulgaris does not adversely influence the quality of sleep. Giornale Italiano di Dermatologia e Venereologia 2013;148(6):655-59.

50. Balta I, Karadag AS, Selek S, et al. General psychiatric symptoms, quality of sleep, and coping strategies in patients with psoriasis vulgaris. International Journal of Dermatology 2016;55(1):60-64.

51. Lou P, Qin Y, Zhang P, et al. Association of sleep quality and quality of life in type 2 diabetes mellitus: A cross-sectional study in China. Diabetes Research and Clinical Practice 2015;107(1):69-76.

52. Gezer O, Batmaz I, Sariyildiz MA, et al. Sleep quality in patients with psoriatic arthritis. International Journal of Rheumatic Diseases 2014.

53. Punjabi NM. The epidemiology of adult obstructive sleep apnea. Proceedings of the American Thoracic Society 2008;5(2):136-43.

54. Karaca S, Fidan F, Erkan F, et al. Might psoriasis be a risk factor for obstructive sleep apnea syndrome? Sleep and Breathing 2013;17(1):275-80.

55. Papadavid E, Vlami K, Dalamaga $M$, et al. Sleep apnea as a comorbidity in obese psoriasis patients: a cross-sectional study. Do psoriasis characteristics and metabolic parameters play a role? Journal of the European Academy of Dermatology and Venereology 2013;27(7):82026.

56. Taheri S, Lin L, Austin $D$, et al. Short sleep duration is associated with reduced leptin, elevated ghrelin, and increased body mass index. PLoS medicine 2004;1(3):210.

57. Yaggi HK, Araujo AB, McKinlay JB. Sleep duration as a risk factor for the development of type 2 diabetes. Diabetes care 2006;29(3):657-61.

58. Gangwisch JE, Heymsfield SB, Boden-Albala B, et al. Sleep duration as a risk factor for diabetes incidence in a large US sample. Sleep 2007;30(12):1667.

59. Gangwisch JE, Heymsfield SB, Boden-Albala B, et al. Short sleep duration as a risk factor for hypertension analyses of the first national health and nutrition examination survey. hypertension 2006;47(5):833-39.

60. AASM. International Classification of Sleep Disorders, 3rd Edition: American Academy Of Sleep Medicine, 2014.

61. Morin $\mathrm{CM}$, Rodrigue $\mathrm{S}$, Ivers $\mathrm{H}$. Role of stress, arousal, and coping skills in primary insomnia. Psychosomatic Medicine 2003;65(2):259-67.

62. Bonnet MH, Arand DL. Hyperarousal and insomnia: state of the science. Sleep medicine reviews 2010;14(1):9-15.

63. de Zambotti M, Covassin N, de Min Tona G, et al. Sleep onset and cardiovascular activity in primary insomnia. Journal of sleep research 2011;20(2):318-25.

64 . Bonnet $\mathrm{M}$, Arand $\mathrm{D}$. Insomnia, metabolic rate and sleep restoration. Journal of internal medicine 2003;254(1):23-31.

65. Vgontzas AN, Bixler EO, Lin H-M, et al. Chronic insomnia is associated with nyctohemeral activation of the hypothalamic-pituitary-adrenal axis: clinical implications. The Journal of Clinical Endocrinology \& Metabolism 2001;86(8):3787-94.

66. Nofzinger EA, Buysse DJ, Germain A, et al. Functional neuroimaging evidence for hyperarousal in insomnia. American Journal of Psychiatry 2004;161(11):2126-28.

This article is protected by copyright. All rights reserved. 
67. Perlis ML, Smith MT, Andrews PJ, et al. Beta/Gamma EEG activity in patients with primary and secondary insomnia and good sleeper controls. Sleep 2001;24(1):110-17.

68. Young T, Peppard PE, Taheri S. Excess weight and sleep-disordered breathing. Journal of Applied Physiology 2005;99(4):1592-99.

69. Armstrong A, Harskamp C, Armstrong E. The association between psoriasis and obesity: a systematic review and meta-analysis of observational studies. Nutrition \& Diabetes 2012;2(12):e54.

70. Arican O, Aral M, Sasmaz S, et al. Serum levels of TNF- $\alpha$, IFN- - , IL-6, IL-8, IL-12, IL-17, and IL-18 in patients with active psoriasis and correlation with disease severity. Mediators of Inflammation 2005;2005(5):273-79.

71. Minoguchi K, Tazaki T, Yokoe T, et al. Elevated production of tumor necrosis factor- $\alpha$ by monocytes in patients with obstructive sleep apnea syndrome. CHEST Journal 2004;126(5):1473-79.

72. Lowes MA, Kikuchi T, Fuentes-Duculan J, et al. Psoriasis vulgaris lesions contain discrete populations of Th1 and Th17 T cells. Journal of Investigative Dermatology 2008;128(5):120711.

73. Kagami S, Rizzo HL, Lee JJ, et al. Circulating Th17, Th22, and Th1 cells are increased in psoriasis. Journal of Investigative Dermatology 2010;130(5):1373-83.

74. Hirotsu C, Noqueira H, Albuquerque R, et al. The bidirectional interactions between psoriasis and obstructive sleep apnea. International Journal of Dermatology 2015;54(12):1352-58.

75. Pataka A, Daskalopoulou E, Kalamaras G, et al. Evaluation of five different questionnaires for assessing sleep apnea syndrome in a sleep clinic. Sleep medicine 2014;15(7):776-81.

76. McNicholas W, Bonsignore M, B26 MCoECA. Sleep apnoea as an independent risk factor for cardiovascular disease: current evidence, basic mechanisms and research priorities. European Respiratory Journal 2007;29(1):156-78.

77. Yaggi HK, Concato J, Kernan WN, et al. Obstructive sleep apnea as a risk factor for stroke and death. New England Journal of Medicine 2005;353(19):2034-41.

78. Tregear S, Reston J, Schoelles K, et al. Obstructive sleep apnea and risk of motor vehicle crash: systematic review and meta-analysis. J Clin Sleep Med 2009;5(6):573-81.

79. Lavie $P$, Herer $P$, Hoffstein V. Obstructive sleep apnoea syndrome as a risk factor for hypertension: population study. Bmj 2000;320(7233):479-82.

80. Yoo S-S, Gujar N, Hu P, et al. The human emotional brain without sleep-a prefrontal amygdala disconnect. Current Biology 2007;17(20):R877-R78.

81. Gujar N, Yoo S-S, Hu P, et al. Sleep deprivation amplifies reactivity of brain reward networks, biasing the appraisal of positive emotional experiences. The Journal of neuroscience 2011;31(12):4466-74.

82. Aoki T, Kushimoto H, Hishikawa $\mathrm{Y}$, et al. Nocturnal scratching and its relationship to the disturbed sleep of itchy subjects. Clinical and Experimental Dermatology 1991;16(4):268-72.

83. Savin J, Paterson W, Oswald I, et al. Further studies of scratching during sleep. British Journal of Dermatology 1975;93(3):297-302.

84. Globe D, Bayliss MS, Harrison DJ. The impact of itch symptoms in psoriasis: results from physician interviews and patient focus groups. Health Qual Life Outcomes 2009;7(1):62.

85. Yosipovitch G, Goon A, Wee J, et al. The prevalence and clinical characteristics of pruritus among patients with extensive psoriasis. British Journal of Dermatology 2000;143(5):969-73.

86. Nigam G, Riaz M, Hershner SD, et al. Sleep Related Scratching: A Distinct Parasomnia. J Clin Sleep Med 2016;12:139-42.

87. Reich A, Hrehorow E, Szepietowski JC. Pruritus is an important factor negatively influencing the well-being of psoriatic patients. Acta Dermato-Venereologica 2010;90(3):257-63.

88. Gupta MA, Gupta AK, Schork NJ, et al. Depression modulates pruritus perception: a study of pruritus in psoriasis, atopic dermatitis, and chronic idiopathic urticaria. Psychosomatic Medicine 1994;56(1):36-40.

This article is protected by copyright. All rights reserved. 
89. Baglioni C, Riemann D. Is chronic insomnia a precursor to major depression? Epidemiological and biological findings. Current psychiatry reports 2012;14(5):511-18.

90. Augustin M, Reich K, Reusch M, et al. Health services research in psoriasis-the German approach. Dermatology 2009;218(4):293-301.

91. Zhang B, Wing Y. Sex differences in insomnia: a meta-analysis. Sleep 2006;29(1):85.

92. Lund $H G$, Reider $B D$, Whiting $A B$, et al. Sleep patterns and predictors of disturbed sleep in a large population of college students. Journal of adolescent health 2010;46(2):124-32.

93. Miller CB, Gordon CJ, Toubia L, et al. Agreement between simple questions about sleep duration and sleep diaries in a large online survey. Sleep Health 2015;1(2):133-37.

94. Strober B, Sobell J, Duffin K, et al. Sleep quality and other patient-reported outcomes improve after patients with psoriasis with suboptimal response to other systemic therapies are switched to adalimumab: results from PROGRESS, an open-label Phase IIIB trial. British Journal of Dermatology 2012;167(6):1374-81.

95. Wu C-Y, Chang Y-T, Juan C-K, et al. Depression and Insomnia in Patients With Psoriasis and Psoriatic Arthritis Taking Tumor Necrosis Factor Antagonists. Medicine 2016;95(22):e3816.

This article is protected by copyright. All rights reserved. 


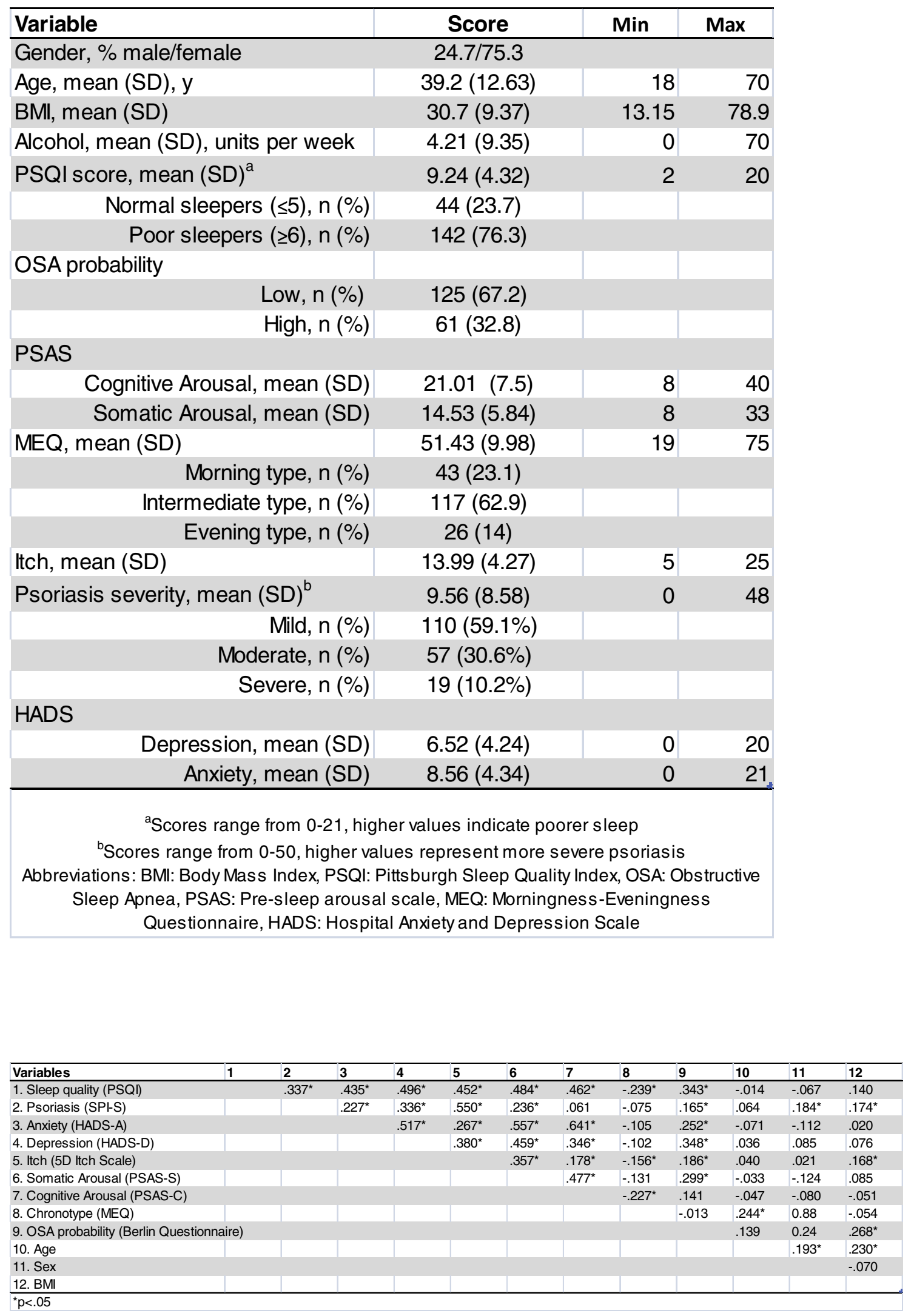

This article is protected by copyright. All rights reserved. 


\begin{tabular}{|c|c|c|c|c|c|c|c|}
\hline & Predictor & b & SE & $\bar{\beta}$ & $t$ & $p$ & $\mathbf{R}^{2}$ \\
\hline \multirow[t]{6}{*}{ Model } & & & & & & & .430 \\
\hline & Itch & .263 & .063 & .260 & 4.16 & .000 & \\
\hline & Cognitive Arousal & .152 & .043 & .264 & 3.54 & .001 & \\
\hline & Depression & .241 & .071 & .237 & 3.39 & .001 & \\
\hline & Somatic Arousal & .124 & .054 & .168 & 2.31 & .022 & \\
\hline & Anxiety & -.020 & .083 & -.020 & -.24 & .809 & \\
\hline \multicolumn{8}{|c|}{ Dependent variable: Sleep quality (PSQI total) } \\
\hline \multicolumn{8}{|c|}{$\begin{array}{l}\text { b, unstandardised regression coefficient; SE, standard error; } \beta \text {, standardised regression coefficient; } t \text {, obtained t-value; } p \text {, } \\
\text { probaility; } R^{2} \text {, proportion of variance explained }\end{array}$} \\
\hline
\end{tabular}

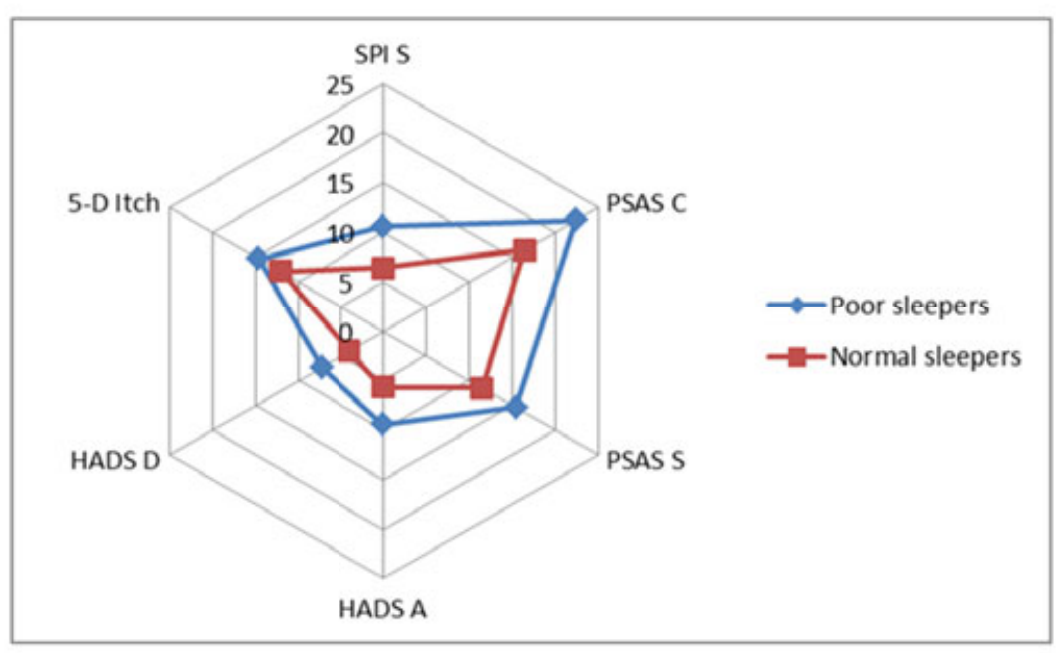

